\title{
The effect of phacoemulsification on late bleb failure or intraocular pressure in patients with glaucoma: a systematic review
}

REVIEW

This article was published in the following Dove Press journal:

Clinical Ophthalmology

5 July 2012

Number of times this article has been viewed

\section{Vasileios G Peponis* \\ Spyridon E Chalkiadakis* \\ Michail C Katzakis \\ Efstratios A Parikakis}

Ophthalmiatreio Athens Eye Hospital, Second Ophthalmology Department,

Athens, Greece

*These authors contributed equally in writing the manuscript
Correspondence: Spyridon E Chalkiadakis Ophthalmiatreio Athens Eye Hospital, Second Eye Clinic, Eleftheriou Venizelou 26, Athens 10672, Greece

Tel +302103623191

$\mathrm{Fax}+302103608660$

Email schalkiad@med.uoa.gr
Abstract: The purpose of our systematic review is to document the adverse events that follow phacoemulsification in eyes with trabeculectomy due to glaucoma and to determine whether phacoemulsification jeopardizes the survival of the trabeculectomy. Our research was based on English- and non-English-language articles obtained using the Medline, Embase, Web of Science and Scopus databases. Additional studies were identified by searching bibliographies in the British Library and abstracts presented at the Association for Research in Vision and Ophthalmology annual meetings. Search terms included randomized controlled trial, controlled clinical trial, random allocation, double-blind method, matched studies and trabeculectomy failure, glaucoma-filtering operation failure, bleb failure and cataract surgery or phacoemulsification. Only prospective or retrospective matched studies testing the survival of a trabeculectomy alone versus clear corneal phacoemulsification after a trabeculectomy in patients with glaucoma were included. Data were independently extracted by two authors using predefined data fields. PubMed yielded 152 results, Scopus 235, Embase 222, and Web of Science (science citation index) 216. We read the abstracts of all the trials, and after reading the full text of 31 studies, we decided that 13 studies should be comprehensively evaluated. Current evidence does not allow us to draw safe conclusions on the scientific question so far.

Keywords: bleb failure, cataract, glaucoma, phacoemulsification, trabeculectomy

\section{Introduction}

In the past, a number of studies ${ }^{1,2}$ have given insight into the epidemiology of primary open-angle glaucoma. For Caucasians, it is estimated that almost $2 \%$ of the population will suffer from the disease, and for Afro-Caribbeans this percentage goes to almost $8 \%$. According to the World Health Organization, age-related cataract causes 48\% of world blindness. In the United States, age-related lenticular changes have been reported in $42 \%$ of those between the ages of 52 and 64 years, $60 \%$ of those between the ages of 65 and 74 years, and $91 \%$ of those between the ages of 75 and 85 years. ${ }^{3,4}$ It is therefore almost inevitable that a glaucoma patient will sooner or later need to undergo cataract surgery independently from his chronic disease.

The objective of the following systematic review is to examine whether there is strong evidence in order to draw safe conclusions on the long-term survival of a trabeculectomy performed before phacoemulsification. ${ }^{5-7}$

\section{Methods}

We looked for matched studies that compared in a prospective or retrospective way the adverse events after a trabeculectomy alone versus phacoemulsification after an 
uncomplicated previous trabeculectomy. Participants of any age with open-angle glaucoma were considered. No limits were applied for language, and we were prepared to translate foreign papers as needed. This search was applied to Medline, Scopus, Embase, the Web of Science (science citation index), and the Cochrane database. The last search was run on February 1, 2012. In addition, we searched the online contents of the British Library and abstracts presented at annual meetings of the Association for Research in Vision and Ophthalmology (ARVO). We used the following search terms to search all trial registers and databases: randomized controlled trial, controlled clinical trial, random allocation, double-blind method, matched study and trabeculectomy failure, glaucoma filtering operation failure, bleb failure and cataract surgery or phacoemulsification. Eligibility assessment was performed independently in an unblinded standardized manner by two reviewers. Disagreements were resolved by discussion between the two; if no agreement could be reached, a third author would decide. In designing the study protocol, we searched primarily for randomized controlled trials (RCTs) to be included. Nonetheless, no author was able to identify one, and therefore, the study design had to be changed. We searched the Cochrane database for similar registrations and found none. Information was extracted from each included study on: (1) characteristics of the study participants and the inclusion and exclusion criteria; (2) type of intervention; (3) type of outcome measure (including visual acuity, intraocular pressure [IOP], number of antiglaucoma drugs used, or need for a secondary antiglaucoma surgery). To ascertain the validity of eligible studies, a pair of authors working independently determined the adequacy of allocation. To explore variability in study results (heterogeneity), we specified the following hypotheses before conducting the analysis. We hypothesized that effect size may differ according to the methodological quality of the study. The primary outcome measure was the statistical significance of the progressive IOP modification before and after phacoemulsification in eyes with previous trabeculectomy.

\section{Results}

A total of 13 studies were identified for inclusion in the review. Two abstracts from the ARVO meetings did not provide full texts, which were necessary to assess the eligibility of the studies, and were not included. All of the studies finally selected for the review were nonrandomized matched studies published in English. None of the studies were multicenter. In all studies, the primary outcome assessed was the postoperative variation of IOP. The secondary and additional outcomes considered were the number of antiglaucoma medications used and the bleb morphology. No study included morbidity and costs as outcomes. The timing of outcome measures was variable and could include monthly investigations, evaluations every 3 months, or a single final evaluation. The first clinical study assessed was from Wang et al. ${ }^{8}$ The main outcome measures for this study were the IOP variation after the phacoemulsification in trabeculectomized eyes and the bleb morphology. The study included 27 eyes and concluded that cataract surgery adversely affects trabeculectomy, especially in cases where there is already an initial failure of the bleb. Inal et $\mathrm{al}^{9}$ published a controlled study that prospectively assessed completed phacoemulsifications in trabeculectomized eyes as compared to isolated cases of trabeculectomy. Nevertheless, the interventions were retrospective and not current. The study and control group each comprised 30 patients with primary open-angle glaucoma. The study demonstrated that the success of filtering surgery gradually diminished, and the degree of IOP control worsened progressively in a timedependent manner. In 2005, Ehrnrooth et $\mathrm{al}^{10}$ conducted a retrospective study in order to evaluate risk indicators for cataract surgery and the effect of phacoemulsification on IOP control in eyes that had undergone trabeculectomy. From a pool of 138 trabeculectomized patients, 47 subsequently underwent cataract surgery and were assessed in the long term. The conclusion of the study was that generally the IOP is maintained stable after cataract surgery, even though there can be cases of late bleb failure. Klink et $\mathrm{al}^{11}$ conducted a prospective study in 2005 with 30 cases and 36 controls. This prospective study concluded that cataract extraction using clear cornea phacoemulsification may be associated with partial loss of the previously functioning filter and with impairment of filtering bleb morphology. Shingleton et $\mathrm{al}^{7}$ conducted a retrospective analysis of the surgical results in his private practice, evaluating the IOP, best-corrected visual acuity (BCVA), and glaucoma medication requirements in patients who underwent phacoemulsification with preexisting glaucoma filters. The study included 58 patients, some of whom had had their cataracts removed through a scleral tunnel or temporal clear cornea. The conclusion was that temporal clear corneal or scleral tunnel phacoemulsification in the setting of a preexisting glaucoma filter was associated with improved BCVA, a small but statistically significant increase in IOP, and stability in the number of glaucoma medicines required for IOP control. A prospective matched study was also conducted by Casson et al. ${ }^{12}$ Two groups comprising 28 patients each were tested for the same working hypothesis, comparing the mean IOP 1 and 2 years after 
phacoemulsification, and the surgical success rate in each group was determined by Kaplan-Meier survival analysis. The authors concluded that phacoemulsification may jeopardize long-term IOP control in individual patients. Rebolleda and Muñoz-Negrete ${ }^{13}$ also contributed by designing and executing a prospective, nonrandomized comparative (self-controlled) study aiming to evaluate the effect of phacoemulsification on IOP control in eyes with a previous functioning filtering bleb in patients who were not taking glaucoma medications. Their conclusions were that phacoemulsification significantly increased the IOP and the number of glaucoma medications necessary in eyes with preexisting functioning filtering blebs. Eyes with higher IOPs before phacoemulsification exhibited worsened postoperative IOP control and bleb failure. In their retrospective study, Mietz et al ${ }^{14}$ concluded that cataract surgery had no markedly negative effect on IOP. Donoso and Rodrigue $z^{15}$ conducted a retrospective study comparing two groups of patients treated with 5-fluorouracile (5-FU). The conclusion was that combined cataract and glaucoma surgery with intraoperative 5-FU was associated with good long-term IOP control. This study focused on the effect of phacoemulsification on trabeculectomy survival and therefore the progression of glaucoma. This represents a good example of whether phacoemulsification adversely affects trabeculectomy over the long term. A study by Caprioli et $\mathrm{al}^{16}$ assessed the safety of temporal clear corneal phacoemulsification in eyes with previous trabeculectomy. In this retrospective case-control study, two groups were matched and assessed. The authors concluded that cataract surgery by temporal clear corneal phacoemulsification in eyes with filtering blebs after trabeculectomy does not adversely affect long-term IOP control. Park et al ${ }^{17}$ conducted a retrospective case control study where they attempted to assess the effect of temporal clear corneal phacoemulsification on IOP in eyes with a prior trabeculectomy. After a careful statistical analysis, the authors concluded that cataract surgery by temporal clear corneal phacoemulsification in eyes with filtering blebs does not adversely affect long-term IOP control. Another study that we assessed was published by Swamynathan et al. ${ }^{18}$ In this retrospective case-control study, the main outcome measure was the IOP before and after phacoemulsification, at various times postoperatively. This study showed that temporal corneal phacoemulsification can affect the long-term IOP control after trabeculectomy with 5-FU or mitomycin C. Halikiopoulos et a ${ }^{19}$ published a prospective case-control study where 68 trabeculectomized patients underwent extraction of their cataracts, either by phacoemulsification or by the extracapsular method. The conclusion of this study was that in the long term, the complication rate of the phacoemulsification was not statistically significant in respect to the extracapsular method with regard to the glaucoma progression.

\section{Discussion}

A review of the literature resulted in a large number of potentially eligible studies that needed to be assessed for inclusion against predetermined criteria; only a small proportion of these were eventually included in the review (Tables 1 and 2). The process for selecting the studies was explicit and conducted in such a way as to minimize the risk of errors and bias. The process by which decisions on the selection of studies were made was specified in a preliminary meeting of the authors that clarified these issues, including who would carry out each stage and how it would be performed. The aim of the selection process was to ensure that all relevant studies would be included in the review. As already known, the types of study used to assess the effects of interventions can be arranged into a hierarchy, based broadly on their susceptibility to bias. Although the RCTs are considered the best study design with which to evaluate the effect of an intervention, in cases where it is unworkable or unethical to randomize participants, a quasi-experimental or an observational design may instead have to be used. Simply grading studies using this hierarchy does not provide an adequate assessment of study quality, because it does not take variations in quality among studies of the same design into account. Even RCTs can be implemented in such a way that findings are likely to be seriously biased and therefore of little value in decision-making. Therefore, it is important to consider the individual aspects of the study design that may introduce bias rather than focusing on the descriptive label used. This is particularly important for the description of nonrandomized studies. Wang et al ${ }^{8}$ presented a prospective study where preoperative IOP and two parameters of the ultrasound biomicroscopy images, including visibility of a route under the scleral flap and reflectivity inside the bleb, were evaluated for an association with postoperative success rate, using Kaplan-Meier survival analysis. An important advantage of the Kaplan-Meier curve is that the method can take some types of censored data into account, particularly if a patient withdraws from a study, ie, is lost from the sample before the final outcome is observed. The same statistical method was also used by Mietz et al. ${ }^{14}$ In the study by Inal et al, ${ }^{9}$ the data were collected retrospectively, even though success rates were investigated by Kaplan-Meier survival analysis, and the factors influencing final success were submitted to logistic 
Table I Summary of studies included

\begin{tabular}{|c|c|c|c|c|}
\hline Authors & $\begin{array}{l}\text { Number } \\
\text { of participants }\end{array}$ & $\begin{array}{l}\text { Number of matched } \\
\text { participants }\end{array}$ & Antimetabolites used & Study design \\
\hline Wang et al & 27 & Self-control & Yes, not specified & Prospective \\
\hline Inal et al & 30 & 30 & No & Prospective controlled \\
\hline Ehrnrooth et al & 46 & 98 & No & Retrospective controlled \\
\hline Klink et al & 30 & Self-control & Yes, in six cases & Prospective \\
\hline Shingleton et al & 58 & Self-control & Mitomycin C (MMC) in 51 eyes & Retrospective \\
\hline Casson et al & 28 & 28 & 5-fluorouracile (5-FU) & Prospective controlled \\
\hline $\begin{array}{l}\text { Rebolleda and } \\
\text { Muñoz-Negrete }\end{array}$ & 49 & Self-control & MMC in six eyes & $\begin{array}{l}\text { Prospective, nonrandomized } \\
\text { comparative (self-controlled) trial }\end{array}$ \\
\hline Mietz et al & 107 & Self-control & $M M C$ in six eyes & Retrospective \\
\hline Donoso and Rodriguez & 22 & 18 & $5-\mathrm{FU}$ & Retrospective matched \\
\hline Caprioli et al & 40 & 40 & $5-\mathrm{FU}$ in 18 eyes & Retrospective case-control study \\
\hline Park et al & 40 & 40 & $5-\mathrm{FU}$ & Retrospective case-control study \\
\hline Swamynathan et al & 29 & 29 & 5-FU or MMC & Retrospective case-control study \\
\hline Halikiopoulos et al & 68 & Self-control & No & Prospective \\
\hline
\end{tabular}

regression analysis. This latter approach is used extensively in the medical sciences to predict a patient's propensity to a certain event. The study by Ehrnrooth et a ${ }^{10}$ was a retrospective case-control investigation; the paper from Klink et al ${ }^{11}$ and the case-control study by Halikiopoulos et $\mathrm{al}^{19}$ were prospective studies. Their statistical analysis was based upon standard deviation calculation and extrapolation of the clinical statistical significance ( $P$-value), which limited the strength of the results. Shingleton et $\mathrm{al}^{7}$ used the same statistical methods, but also introduced the best way to clinically assess BCVA using the logMAR scale. The prospective, matched study by Casson et al, ${ }^{12}$ the prospective, nonrandomized comparative (self-controlled) study by Rebolleda and Muñoz-Negrete, ${ }^{13}$ and the retrospective case-control study by Caprioli et al ${ }^{16}$ used the same statistical methods, with the limitations mentioned above. A very good impression comes from the study by Donoso and Rodriguez. ${ }^{15}$ They used the log-rank test (sometimes called the Mantel-Cox test), which is a hypothesis test to compare the survival distributions of two samples. It is widely used in clinical trials to establish the efficacy of a new treatment compared to a control treatment when the measurement is the time to event (such as the time from initial treatment to IOP spikes). Lastly, another source of major bias in the finalization of the results is that during the execution of the trabeculectomy, some surgeons used different antimetabolites and some used none, such as in the studies of Park et al ${ }^{17}$ and Swamynathan et al. ${ }^{18}$ It is difficult to assess the influence of antifibrotic therapy on the long-term survival of a trabeculectomy when associated with phacoemulsification because statistical variables increase exponentially and add further to the scientific dilemma.

In conclusion, our systematic review sought to gather all the available evidence in favor or against the question of whether phacoemulsification should be performed with or after a trabeculectomy. Evidence to date has not answered this question comprehensively.

Table 2 Long-term variations of quality controls

\begin{tabular}{|c|c|c|c|c|c|}
\hline Authors & Intraocular pressure & Medications taken & Visual acuity/fields & Bleb survival & Final result \\
\hline Wang et al & Increased & N/A & $N / A$ & Non modified & Negative \\
\hline Inal et al & Increased in both groups & Increased & $\mathrm{N} / \mathrm{A}$ & Compromised & Inconclusive \\
\hline Ehrnrooth et al & Increased & Increased & $\mathrm{N} / \mathrm{A}$ & Compromised & Inconclusive \\
\hline Klink et al & Increased & $\mathrm{N} / \mathrm{A}$ & $N / A$ & Compromised & Negative \\
\hline Shingleton et al & Increased & Stable & Improved & N/A & Inconclusive \\
\hline Casson et al & Increased & Increased & N/A & Compromised & Negative \\
\hline Rebolleda and Muñoz-Negrete & Increased & Increased & Reduced & Compromised & Negative \\
\hline Mietz et al & Unchanged on average & Unchanged on average & Improved & N/A & $\begin{array}{l}\text { Relatively favorable } \\
\text { results }\end{array}$ \\
\hline Donoso and Rodriguez & Reduced & None & $\mathrm{N} / \mathrm{A}$ & N/A & Positive \\
\hline Caprioli et al & Similar & N/A & $\mathrm{N} / \mathrm{A}$ & N/A & Positive \\
\hline Park et al & Similar & N/A & N/A & N/A & Positive \\
\hline Swamynathan et al & Increased & $\mathrm{N} / \mathrm{A}$ & Improved & N/A & Negative \\
\hline Halikiopoulos et al & Increased & N/A & Improved & N/A & Negative \\
\hline
\end{tabular}

Abbreviation: N/A, not applicable. 


\section{Disclosure}

No financial and (or) proprietary interests are stated regarding this manuscript. The authors received no funding/support during the preparation of the manuscript.

\section{References}

1. Tielsch JM, Sommer A, Katz J, Royall RM, Quigley HA, Javitt J. Racial variations in the prevalence of primary open-angle glaucoma. The Baltimore Eye Survey. JAMA. 1991;266:369-374.

2. Klein BE, Klein R, Sponsel WE, et al. Prevalence of glaucoma. The Beaver Dam Eye Study. Ophthalmology. 1992;99:1499-1504.

3. Sperduto RD, Seigel D. Senile lens and senile macular changes in a population-based sample. Am J Ophthalmol. 1980;90:86-91.

4. Kahn HA, Leibowitz HM, Ganley JP, et al. The Framingham Eye Study. I. Outline and major prevalence findings. Am J Epidemiol. 1977; 106:17-32.

5. Crichton AC, Kirker AW. Intraocular pressure and medication control after clear corneal phacoemulsification and AcrySof posterior chamber intraocular lens implantation in patients with filtering blebs. J Glaucoma. 2001;10:38-46.

6. Derbolav A, Vass C, Menapace R, Schmetterer K, Wedrich A. Long-term effect of phacoemulsification on intraocular pressure after trabeculectomy. J Cataract Refract Surg. 2002;28:425-430.

7. Shingleton BJ, O'Donoghue MW, Hall PE. Results of phacoemulsification in eyes with preexisting glaucoma filters. J Cataract Refract Surg. 2003;29:1093-1096.

8. Wang X, Zhang H, Li S, Wang N. The effects of phacoemulsification on intraocular pressure and ultrasound biomicroscopic image of filtering bleb in eyes with cataract and functioning filtering blebs. Eye (Lond). 2009;23:112-116.

9. Inal A, Bayraktar S, Inal B, Bayraktar Z, Yilmaz OF. Intraocular pressure control after clear corneal phacoemulsification in eyes with previous trabeculectomy: a controlled study. Acta Ophthalmol Scand. 2005;83: 554-560.
10. Ehrnrooth P, Lehto I, Puska P, Laatikainen L. Phacoemulsification in trabeculectomized eyes. Acta Ophthalmol Scand. 2005;83: 561-566.

11. Klink J, Schmitz B, Lieb WE, et al. Filtering bleb function after clear cornea phacoemulsification: a prospective study. Br J Ophthalmol. 2005;89:597-601.

12. Casson R, Rahman R, Salmon JF. Phacoemulsification with intraocular lens implantation after trabeculectomy. J Glaucoma. 2002;11: 429-433.

13. Rebolleda G, Muñoz-Negrete FJ. Phacoemulsification in eyes with functioning filtering blebs: a prospective study. Ophthalmology. 2002;109: 2248-2255.

14. Mietz H, Andresen A, Welsandt G, Krieglstein GK. Effect of cataract surgery on intraocular pressure in eyes with previous trabeculectomy. Graefes Arch Clin Exp Ophthalmol. 2001;239:763-769.

15. Donoso R, Rodriguez A. Combined versus sequential phacotrabeculectomy with intraoperative 5-fluorouracil. J Cataract Refract Surg. 2000;26: 71-74.

16. Caprioli J, Park HJ, Kwon YH, Weitzman M. Temporal corneal phacoemulsification in filtered glaucoma patients. Trans Am Ophthalmol Soc. 1997;95:153-167; discussion 167-170.

17. Park HJ, Kwon YH, Weitzman M, Caprioli J. Temporal corneal phacoemulsification in patients with filtered glaucoma. Arch Ophthalmol. 1997;115:1375-1380.

18. Swamynathan K, Capistrano AP, Cantor LB, WuDunn D. Effect of temporal corneal phacoemulsification on intraocular pressure in eyes with prior trabeculectomy with an antimetabolite. Ophthalmology. 2004; 111:674-678.

19. Halikiopoulos D, Moster MR, Azuara-Blanco A, et al. The outcome of the functioning filter after subsequent cataract extraction. Ophthalmic Surg Lasers. 2001;32:108-117.
Clinical Ophthalmology

\section{Publish your work in this journal}

Clinical Ophthalmology is an international, peer-reviewed journal covering all subspecialties within ophthalmology. Key topics include: Optometry; Visual science; Pharmacology and drug therapy in eye diseases; Basic Sciences; Primary and Secondary eye care; Patient Safety and Quality of Care Improvements. This journal is indexed on

Submit your manuscript here: http://www.dovepress.com/clinical-ophthalmology-journal

\section{Dovepress}

PubMed Central and CAS, and is the official journal of The Society of Clinical Ophthalmology (SCO). The manuscript management system is completely online and includes a very quick and fair peer-review system, which is all easy to use. Visit http://www.dovepress.com/ testimonials.php to read real quotes from published authors. 